\title{
Augmented Reality Enhanced Ubiquitous-Learning in Museum
}

\author{
Yi-Hsien Lin, Shu-Hsuan Chang, Tien-Chi Huang, Yu-Ting Lin, and Yu-Jie Chen
}

\begin{abstract}
Museums are ideal informal learning environments. This study develops an augmented reality (AR) system (APP and management platform) for visitors to actively explore learning resources in museum. There are three main parts of the system, public mode (for adults), child mode (for elementary or high school students), and backend management platform (for museum manager). To arouse visitors' motivation, this study adopts problem-based learning (PBL) as main theory base of the system. Along with iBeacon indoor positioning technology, the AR (augmented reality) is adopted to display questions (inspire visitors thinking and interaction) nearby the exhibition items. In this sense, the learning may actually happen in museums.
\end{abstract}

Index Terms-Augmented reality, learning in museum, problem-based learning, iBeacon, indoor positioning.

\section{INTRODUCTION}

Museums are ideal informal learning environments. This type of informal education occurs outside of the school, where learners fulfill their learning objectives through their own interest in learning and systematically acquire information.

In the words of Francis Bacon, "Tell me and I forget. Teach me and I may remember. Involve me and I learn.", which notes the importance of interaction in learning process. Although learning resources available through museums abound, the traditional one-to-many guidance could lead to visitors overlook the educational value and meaning of the exhibitions. On the others hand, museum once argue that the method of "allowing the works to speak for themselves" is only meaningful for experts with prior knowledge or an understanding of related concepts [1]. Furthermore, in traditional museums, museum guides are paired with groups of many visitors, meaning that visitors may be restricted by spatial factors, making it difficult to fully appreciate exhibited works. Despite the fact that each visitor is now able to visit exhibitions at their own pace as a result of various technologies maturing over the past several years, such as the development of personal audio guide devices, the one-way explanations of museum content do not allow them to reflect

Manuscript received January 13, 2019; revised May 24, 2019.

Yi-Hsien Lin is with the Lukan Senior High School, Taiwan (e-mail: yslin@mail.lksh.chc.edu.tw)

Shu-Hsuan Chang is with the Department of Industrial Education and Technology. She is also with e-Learning Center, National Changhua University of Education (NCUE), Taiwan (e-mail: shc@cc.ncue.edu.tw).

Tien-Chi Huang is with the Department of Information Management, National Taichung University of Science and Technology, Taiwan (e-mail: tchuang@ nutc.edu.tw).

Yu-Ting Lin and Yu-Jie Chen are with National Taichung University of Science and Technology, Taiwan (e-mail: abc850927@gmail.com, yujiemilk@gmail.com). on and derive inspiration from the tour. In other words, museum guides should help to communicate museum information, and interactivity helps learners understand that information.

For this reason, this study aims to build a problem-based augmented reality (AR) learning platform to help museums receive visitors of all ages in order to improve the educational value of museums. In this AR platform, a problem-based learning (PBL) strategy is adopted, which uses real-world situations or problems to guide visitors' thinking [2]. In this process, the platform emphasizes to visitors the importance of defining problems and establishing hypotheses, as well as collecting and analyzing information to improve their critical and reflective learning abilities. Based on the above, the use of problems to trigger the publics' active reflection can also generate educational value for museums. AR technology uses handheld screens to augment the learning information presented in real environments, thereby providing learning interactivity. By combining these two strategies, visitors are encouraged to actively reflect and interact with one another.

Regarding technology, AR and iBeacon indoor positioning sensor technologies comprise the technological system proposed in this study. PBL environments serve as the main axis of the system, allowing for the establishment of a more ideal museum learning environment.

In this environment, problems for visitors of different age groups can be established, enabling them to actively think about problems related to specific exhibition works or items and gain feedback from reflection. The discussion platform guides visitors to understand the ideas of other people and to debate with one another. This allows visitors to view works from different perspectives, providing a greater variety of paths to obtain information related to an exhibited work Through the process of interacting with an exhibited work, examining opinions or responses different from one's own, and conducting mutual debates, visitors comprehend knowledge, learn, and think.

\section{LITERATURE REVIEW}

\section{A. Museum Guides}

The primary objective of museum guides is to communicate the meaning of exhibition items and provide a wealth of information to guide the public to understand exhibition items on cognitive and emotional levels, thereby achieving the goals of social education. This paper jointly addresses traditional tour guide methods, which can be categorized as staff guides and non-staff guides, as shown in Table I. 
TABLE I: ANALYSIS OF TOUR GUIDE METHODS [3]

\begin{tabular}{|c|c|}
\hline & Staff Guides \\
\hline $\begin{array}{l}\text { Ordinary Guides } \\
\text { (Fixed) }\end{array}$ & \multirow{4}{*}{$\begin{array}{l}\text { Pros: Guides present information in a } \\
\text { detailed and clear manner, and } \\
\text { can engage in real-world } \\
\text { interaction with visitors. } \\
\text { Cons: When there are too many } \\
\text { visitors, guides cannot } \\
\text { individually satisfy the needs } \\
\text { of each visitor, and fixed } \\
\text { presentation sites make it } \\
\text { difficult to see exhibition } \\
\text { items. }\end{array}$} \\
\hline $\begin{array}{c}\text { Exhibition Room } \\
\text { Presentation (Topical) }\end{array}$ & \\
\hline $\begin{array}{c}\text { Q\&A Service } \\
\text { (Q\&A Reception Desk) }\end{array}$ & \\
\hline $\begin{array}{l}\text { Expert Guides } \\
\text { (On-Site Expert } \\
\text { Presentations) }\end{array}$ & \\
\hline \multicolumn{2}{|r|}{ Non-Staff Guides } \\
\hline Description Card & $\begin{array}{l}\text { Pros: Clear and simple explanation of } \\
\text { content, easy to read. } \\
\text { Cons: During busy hours, description } \\
\text { cards are difficult to view. }\end{array}$ \\
\hline Folding Brochure & $\begin{array}{l}\text { Pros: Wealth of guiding information. } \\
\text { Cons: High printing costs, easily } \\
\text { results in wasted resources. }\end{array}$ \\
\hline $\begin{array}{l}\text { Multimedia Guides } \\
\text { (Audio Guides) }\end{array}$ & $\begin{array}{l}\text { Pros: Multimedia is attractive to } \\
\text { visitors and generates interest } \\
\text { in exhibition items. } \\
\text { Cons: Not very interactive with } \\
\text { visitors, vibrant audiovisual } \\
\text { elements can distract visitor } \\
\text { attention from exhibition } \\
\text { items. }\end{array}$ \\
\hline
\end{tabular}

\section{B. Application of AR and Indoor Positioning Sensor Technology in Educational Environments}

AR is a way of integrating the real world and virtual objects, and a technology that can instantaneously generate 3-D interactions. Using a camera, algorithms are executed on the captured image, which allows the user to use their sensory perceptions to directly or indirectly view virtual objects projected onto the real world and to immediately interact with these objects.

Regarding the educational elements of AR technologies, AR has been applied to a variety of educational curricula, making them more dynamic or improving learning outcomes. [4], [5] According to the effects of these on learning performance, AR teaching methods provide students a sense of curiosity, promote their sustained attentiveness, and can effectively increase student motivation, enhancing learning performance. The above research confirms that when applied to learning, AR can improve students' motivations for learning and increase their levels of participation and attentiveness during the learning process.

Thus, this study introduces AR technology into museums and allows users to search for specific icons in exhibition halls and scan these in order to be provided with information from the system. During the process of museum visits, human-machine interaction is used to elevate visitor curiosity and interest in exhibition items and stimulate visitors' motivations for learning, thereby achieving learning efficacy.

Regarding the indoor positioning technology used in this study, iBeacon is a signal transmitter that allows nearby electronic devices to sense and accurately position using low-power Bluetooth technology [6]. When the smartphone app's Bluetooth wireless signal enters the scope of coverage of the transmitter signal, the app automatically receives the tag information. This operation is shown in Fig. 1.

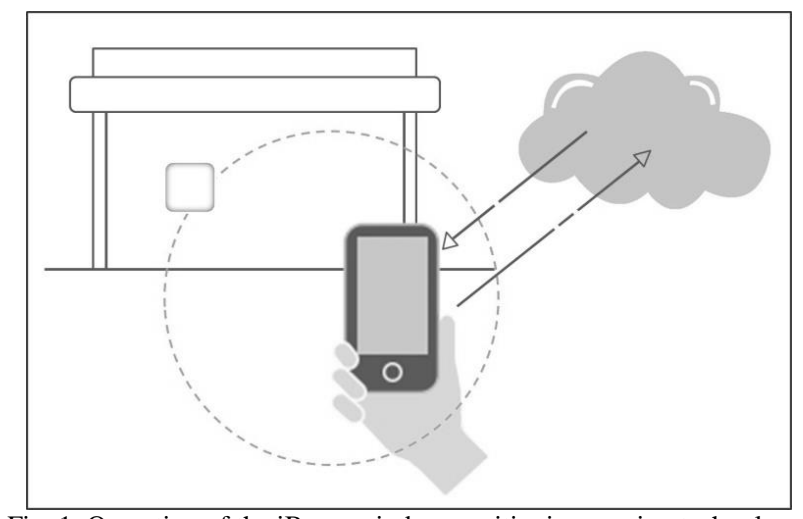

Fig. 1. Operation of the iBeacon indoor positioning sensing technology.

The University of Oklahoma has used iBeacon technology to create virtual tours, allowing students to conveniently search for books and manuscripts in the university's special collections and encouraging them to discover new knowledge. In educational games, the iBeacon Treasure Hunt game uses positioning to emit signals. Each signal gives students a clue to help them advance to the next level, enabling them to use their self-guiding ability to receive rewards.

Therefore, we use iBeacon's push notification function to allow museum visitors to use iBeacon to sense the location of their mobile device and provide information related to exhibition items. In this way, visitors can use their mobile devices to immediately receive text, images, and dedicated multimedia information related to the exhibition item, improving their understanding of the item or enabling them to search for new information related to their questions or reflections on it.

\section{Problem-Based Learning}

PBL was first defined by Barrows and Tamblyn (1980) as follows: "Learning comes from the process by which problems are understood and resolved, and problems are established before learning begins." PBL is an educational method that disrupts traditional educational methods centered on students, and aims to use real-world problems to guide students in active learning [2]. It uses problems to encourage students to use their prior knowledge and search for information, so that they can think, understand problems, and propose problem resolution methods. In this way, PBL can generate deeper learning impressions in students and strengthen their knowledge and understanding.

Scholars have applied PBL in educational strategies and experimental research. These studies used group experiments (where each group contained four students) in which some groups used PBL methods. Through data analysis and interviews, this research confirmed that PBL effectively promotes the learning process and improves "problem solving skills" and other related skills. As such, PBL methods are helpful for improving problem solving and extending thought. [2]

There are various PBL models. This study refers to the five-step learning process proposed by Barrow (1985), the pioneer of PBL. It further combines this with detailed steps of user operation for comparison, and summarizes a museum PBL mode map to clarify the operational state of the system represented by each step, as shown in Fig. 2. 


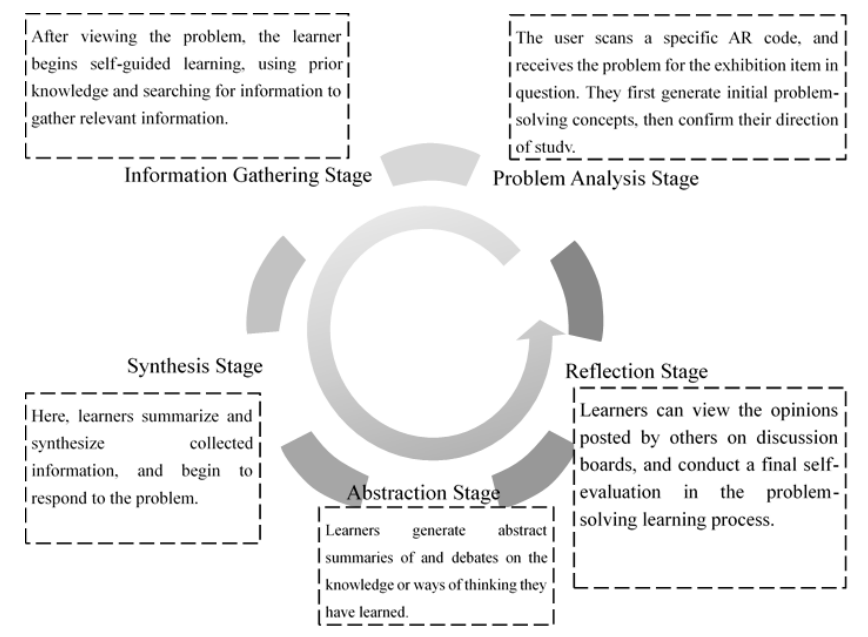

Fig. 2. Museum PBL mode map.

This study enables museum visitors to use their mobile devices during their visit to activate their learning motivation. When the system is used, it is first divided into two modes. The first mode aims to enhance interest in the museum and uses exploration to allow visitors to receive tips and solve problems. The second mode aims to encourage visitors to engage in thinking so that they can solve problems and to view different opinions on discussion boards. PBL environments prevent museum learners from passively receiving information and instructions in a unidirectional manner, causing them to acquire and link new knowledge with prior knowledge through their own learning process.

\section{SYSTEM FRAMEWORK AND TECHNOLOGY APPLICATIONS}

\section{A. System Planning}

The system used in this study was developed for an Android mobile device. The system can be delineated into the mobile application end and server end. The system server uses XAMPP technology to establish a platform and integrates a MySQL database to store new user information. Furthermore, it uses a PHP backend program as a communication language between the front end of the system and database, thereby providing an exhibition site management platform that exhibition site managers can use to remotely alter digital exhibition content at any time according to the needs of the exhibition. The mobile application end of the system is produced with the Unity game engine tool, and embeds Vuforia SDK AR technology to strengthen the interactivity between exhibition items and visitors, helping visitors integrate among the exhibition item learning environment and rooting the system in learning effectiveness. Furthermore, websocket technology is used to instantly transmit information to the database for system analysis and maintenance.

The system is subdivided into three parts: the Android smartphone guide platform, exhibition manager platform, and system database server. The overall system divisions are shown in Fig. 3.

\section{B. Public Mode}

In the public mode, AR technology and integration of an active PBL environment enable users to select from three functions on the main screen to execute operations. First, the AR guide can be used to view information related to the exhibition site in addition to basic methods of operation. Next, $\mathrm{AR}$ is used (Fig. 4) to respond to problems, primarily by scanning specific AR codes at the exhibition site to transmit information. When a user successfully scans the correct AR code, AR is used to display problems on the user's screen, accompanied by 3-D GIFs. Next, users brainstorm based on the problem presented in the $\mathrm{AR}$ response. By design, the problem serves as a starting point and has no standard response, meaning that the responses are stored on the discussion board according to their corresponding topic (Fig. 5) and can be viewed and reflected upon by all users. This is distinct from ordinary methods of viewing exhibitions, and users can search for problems to reflect on. This method is compatible with the process of PBL.

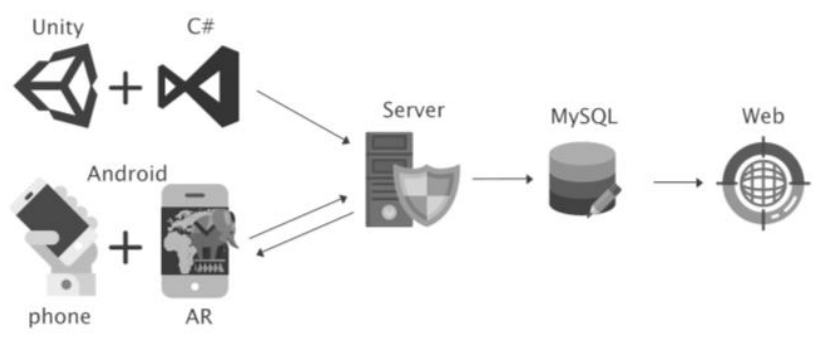

Fig. 3. System technology framework.

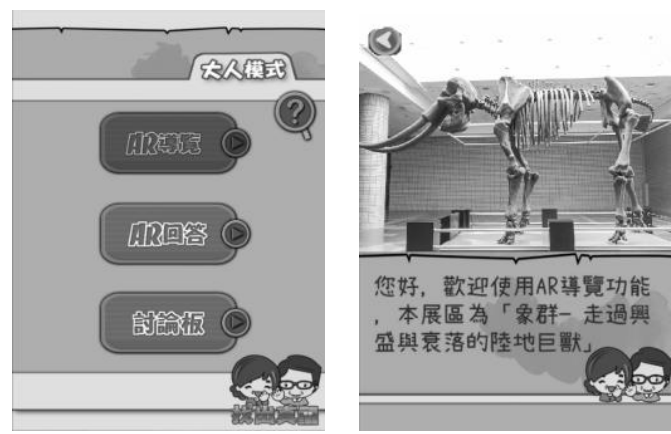

Fig. 4. AR Response (Public mode).

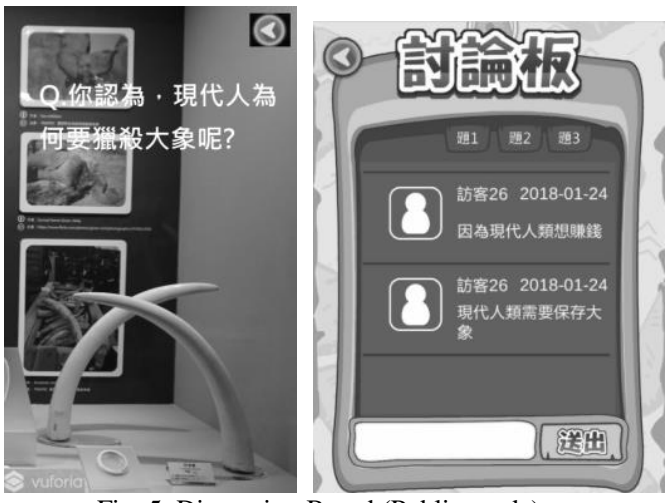

Fig. 5. Discussion Board (Public mode) .

\section{Child Mode}

The design style for this mode employs an adventurous method of presentation, and is well suited for children. First, users can use the map feature to understand the scope of the exhibition site, topic items, and to view tip locations. When users successfully scan the correct QR code, they are shown a congratulatory window, and the progress bar at the top of the screen indicates that the user has advanced one space. The 
discovered topics are saved in the application's record function, where users can view, respond to, and reflect on the topic based on the surrounding exhibition area. Correct responses to each topic presented in this mode can be found at the exhibition site and exhibition items. If the user responds successfully, their progress bar advances one space (two topics are used in this example, which can be altered according to the needs of the exhibition). In addition, the tip function is primarily integrated with the iBeacon sensor technology. If the user cannot scan the correct response, they can approach a tip marker on the map to receive a tip. This helps users scan the correct response.

\section{Backend Management Platform}

The backend management platform is an auxiliary application system constructed for the use of museum staff. It provides functions for visitors to conduct follow-up analysis, a data visualization interface, text placement analysis, and a PBL problem database. The backend management platform makes it convenient for museum staff to manage topics or make revisions, or to view the status of topic responses. For example, museum staff can use the platform to find and delete responses that are indecent or unsuitable for the topic, and to maintain the accuracy of discussion board content. Staff can also use the platform to determine the number of registered users and their age range. As such, museum staff need only use the backend management platform to update and maintain application content, allowing them to conveniently achieve their objectives and greatly reducing maintenance costs.

\section{CONCLUSIONS}

With the rapid development of technology, a wide variety of objects have been integrated with technology. We observed this in the field of informal education, in which we discovered many problems. Therefore, the system developed in this study combines AR and location sensing technology to establish a PBL environment, and uses information technology to assist learning in the field of informal education.

PBL is the main axis around which this system is developed. Based on this, a universal system for informal education environments is established on Android mobile devices. Museum staff can use the web end of the system to easily alter content presented in the app, and users can use their smartphones to directly connect with and learn in the informal education environment. The adult and child modes designed for this system generate different learning experiences according to learners' individual needs, activating learner interest, and utilize interesting problems and tips or other users' views to integrate the user with the informal education environment and allow them to explore and interact with the site. This system aims to provide users with a greater number and breadth of perspectives through the process of learning in informal education environments.

In the future, this system can be applied to many informal education fields and accompany learning environments generated by the system to improve the learning outcomes of individuals within the learning environment. Furthermore, it is hoped that the system can be introduced to schools' off-campus teaching methods, such as trips to corporate offices, museum visits, or topical exhibitions. In this way, the system can improve off-campus teaching, enable students to acquire more information and knowledge, and contribute towards achieving teaching outcomes. Using smart handheld devices and a virtual reality integrated field-based learning system, we hope to create new standards for informal education.

\section{ACKNOWLEDGMENT}

Financial support on this work from the Ministry of Science and Technology, Taiwan (MOST 106-2511-S-025 -003 -MY3)

\section{REFERENCES}

[1] R. Burnham and E. Kai-Kee, "Teaching in the art museum: Interpretation as experience," Getty Publications, 2011.

[2] M. J. Duncan, M. Smith, and K. Cook, "Implementing online problem based learning (PBL) in postgraduates new to both online learning and PBL: An example from strength and conditioning," Journal of Hospitality, Leisure, Sport \& Tourism Education, vol. 12, pp. 79-84, 2013.

[3] J. D. Wineman and J. Peponis, "Constructing spatial meaning: Spatial affordances in museum design," Environment and Behavior, vol. 42 no. 1, pp.86-109, 2010.

[4] J. Kysela and P. Štorková, "Using augmented reality as a medium for teaching history and tourism," Procedia-Social and Behavioral Sciences, vol. 174, pp. 926-931, 2015.

[5] D. Nincarean, M. B. Alia, N. D. A. Halim, and M. H. A. Rahman, "Mobile augmented reality: The potential for education,' Procedia-Social and Behavioral Sciences, vol. 103, pp. 657-664, 2013.

[6] C. Swedberg, "Beacons guide and inform University of Oklahoma students," IOT Journal, 2015.

Copyright (C) 2019 by the authors. This is an open access article distributed under the Creative Commons Attribution License which permits unrestricted use, distribution, and reproduction in any medium, provided the original work is properly cited (CC BY 4.0)

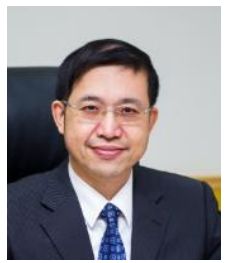

Yi-Hsien Lin is currently a president of National Lukan Senior High School in Changhua and a Ph.D. candidate of NCUE, Taiwan. His research interests include internet ethics and educational technology.

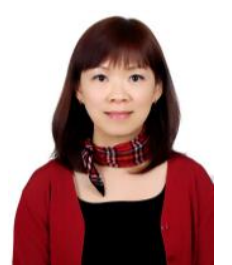

Shu-Hsuan Chang is currently a professor of the Department of Industrial Education and Technology as well as the director of E-Learning Center, National Changhua University of Education (NCUE), Taiwan. She received the B.S. and M.S. degrees in industrial engineering from National Chiao-Tung University, Taiwan, and the Ph.D. degree in the Department of Industrial Education and Technology from NCUE, Taiwan. Her research interests include engineering \& technological education, technology management, innovation management, and photonics.

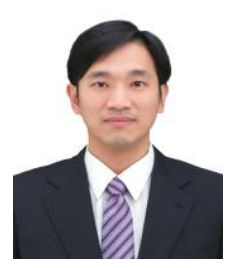

Tien-Chi Huang is an associate professor in the Department of Information Management at National Taichung University of Science and Technology, Taiwan. His current research interests include e-learning, m-learning, u-learning, teaching materia design, and evaluation. Dr. Huang's research is published or is forthcoming in Computers and Education, Journal of Educational Technology \& Society, Telematics and Informatics, Information Fusion, The Electronic Library, Multimedia Systems, Personal and Ubiquitous Computing, Expert Systems with Applications, International Education Studies, and a number of national and international conference proceedings. 


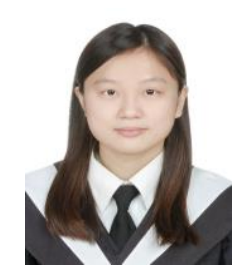

Yu-Ting Lin received her bachelor's degree in 2018 from National Taichung University of Science and Technology. After graduation, she is a programmer and web designer.

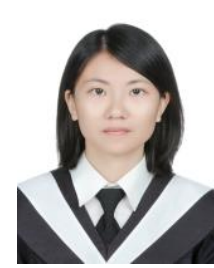

Yu-Jie Chen received a bachelor's degree in 2018 from

National Taichung University of Science and

Technology. Currently she is a Master's Student and her research interests are VR/AR in education. 